\title{
Does Sports and School Run Together? A Needs Analysis of University Student-Athletes
}

\author{
Kıvanç Semiz ${ }^{1}$
}

${ }^{1}$ Giresun University, kivancsemiz@gmail.com

Received: 17.09.2018

doi: $10.30655 /$ besad.2018.10
Accepted: 27.09.2018

url: https://doi.org/10.30655/besad.2018.10

\begin{abstract}
Student-Athletes are experiencing lots of challenges both in sports and education environments. Problems such as identity crisis, which is brought by the struggle to maintain two careers at the same time, force student-athletes to choose one career path or the other. Therefore, the purpose of the study was to reveal the problems and the difficulties experienced by student-athletes in university. A case study was selected as a research design in this study. A total of nine student-athletes (One Football, one Wrestling, two Basketball, four Volleyball, and one Marathon Athletes) was the participants of this study from Giresun University, Turkey. Focus group interviews and reflection notes were done for the data collection. Thematic Content Analysis was used for the data analysis. Three main topics emerged as school-sports $c l u b$ conflicts, stakeholders' expectations and financial anxiety of student-athletes. The absenteeism problem of the student-athletes was seen as the main problem and since the location of the club that students transferred may be changed every year, the students have difficulties to go to the university regularly. Student-athletes are granted permission to go to universities only in the exam weeks by the clubs. Providing technology-integrated instructional designs according to the needs of student-athletes while protecting the level and the quality of instruction and educational gains, with developing new education policies for absenteeism were recommended.
\end{abstract}

Keywords: Dual careers, Student-athletes.

\section{Okul ve Spor Bir Arada Gider mi? Üniversite Sporcu-Öğrencilerinin İhtiyaç Analizi}

\section{$\ddot{\mathbf{O} z}$}

Sporcu öğrencilerin gerek ĕgitim hayatlarında gerekse spor ortamlarında yaşadı̆̆ birçok zorluk bulunmaktadır. İki kariyeri aynı zamanda yürütmeye çalışmanın getirdiği kimlik karmaşası, her iki kariyerin getirdiği sorumlulukların mecbur bıraktığ iki kariyer yolundan birini tercih etmek zorunda bırakılmak, ögrencilerin kariyerlerine devam ettirmeyi zorlaştırmaktadır. Bu çalışmanın amacı sporcu ögrencilerin ihtiyaçlarını belirlemek, spor ve eğitim kariyerlerini sürdürmekte karşılaştıkları sorunları ve beklentilerini ortaya koymaktır. Bu araştırmada durum çalışması deseni kullanılmıştır. Çalışmaya çeşitli kademelerde mücadele eden 1 Futbolcu, 1 güreşşi, 2 basketbolcu, 4 voleybolcu ve 1 atlet olmak üzere 9 sporcu ögrenci katılmıştır. Odak grup görüşmesi ve alan yansıma notları ile veri toplanmıştır. Tematik içerik analizi ile sonuçlar elde edilmiştir. Üç ana tema altında sporcuların ihtiyaçları belirlenmiştir. Bunlar sırasıyla okul-kulüp çatışması, paydaş beklentileri ve sporcu öğrencilerin maddi kazanç kaygısı olarak söylenebilir. Sporcu Öğrencilerin özellikle devamsızlık probleminin okulları ile problemlerinde öne çıktığı, sınav dönemleri haricinde takımlarından izin almada problem yaşadıkları görülmüş̧̈̈r. Her yeni sezonda anlaşılan kulüp ile okulun konumu arasındaki mesafe sürekli değiş̧tiğinden sporcu-ögrencilerin bir ve ya her iki kariyerini bırakmayla yüz yüze kaldıkları görülmüştür. Söz konusu ögrencilerin ihtiyaçlarına özgü ögretim tasarımları sunmada teknolojiden faydalanılması ve devamsızlı konusunda üniversitelerin yeni eğitim politikaları geliştirmesi önerilmektedir. 


\section{Giriş}

Sporcu-öğrenciler antrenmanlar, hazırlık kampları, şampiyonalar ya da maçlar ile meşgul olurken aynı zamanda eğitim kariyerlerini de sürdürmeye çalışmaktadırlar. Çift kariyerli bireyler (Dual Careers) olarak da sözü edilen popülasyonun, antrenörler ve spor yöneticilerinin taleplerini yerine getirmek için çabalarken diğer yandan bağlı bulundukları eğitim kurumunun akademik takvimine ve gerekliliklerine uygun davranmak zorunda kaldıkları görülmektedir (Geraniosova \& Ronkainen, 2015). Yapılan araştırmalarda sporu amatör ya da profesyonel anlamda bir meslek olarak yürütenlerin üniversite öğrenimlerini de beraber yürütmekte zorlanmaları, sporcu öğrencilerle alakalı çalışmalarda özellikle aile, akran, antrenör ve öğretmenlerin desteği ile alakalı araştırmalara ihtiyaç olduğu ortaya konmuştur (Guidotti, Cortis \& Capranica, 2015). Milli sporcu öğrencilerle yapılan bir araştırmada, bu zorlukların başında kamp sayısı ve süresi ile birlikte öğrencinin dönem başına aldığı derslerin sayısı öne çıkmıştır. Sporcu öğrencilerin eğitim hayatları boyunca sadece kamp aralarında ve sınav dönemlerinde okulda bulunabildikleri görülmüştür. (Bayram, Keskin, Kabadayı ve Bostancı, 2016). İspanya'daki elit sporcu öğrencilerle yapılan bir başka araştırmada da zaman yönetiminin en önemli bariyer olarak bulunması bu sonucu destekler niteliktedir (De Subijana, Barriopedro \& Conde, 2015). Genellikle sporcu olduklarından dolayı hayatta elde ettikleri bilgi birikimi ve kazanımlarla eğitim hayatına yöneldiklerinden -ki sporcu öğrencilerin, spor yapmayan öğrencilere oranla daha dişa dönük oldukları (Arslan, Bayraktar \& Erdoğan, 2006) görülmüştür- sporcu kimliğinin yanında bir de öğrenci kimliği geliştirme ve koruma çabasının onlarda bir kimlik karmaşasına yol açtığı bulunmuştur (Lally \& Kerr, 2005; Stambulova Engström, Franck, Linnér \& Lindahl, 2015). Yine bir başka araştırmada da sporcu öğrencilerin diğer üniversite öğrencilerine göre daha düşük kariyer olgunluğuna sahip oldukları bulunmuştur (McQuown Linnemeyer \& Brown, 2010). Öte yandan Türkiye'de yapılan bir başka araştırmada ise sporcu öğrencilerin kariyer değer algıları bakımından diğer öğrencilerden bir farklılıkları bulunmadığı ortaya konmuştur (Karakaya ve ark., 2013).

Peki spor mu okul mu? Her iki kariyeri de devam ettirmeye çalışırken oluşan kaygı ve belirsizlik, öğrencilerin kariyerlerine devam etmede kafa karışıklığına yol açmaktadır (Pato ve ark., 2018). Sporcuların ve ailelerin başarı beklentileri, kariyer sürecini tükenmişlik sendromuna ve sporu ya da okulu bırakmaya kadar götürebilmektedir (Sorkkila, Aunola \& Ryba, 2017). İki kariyer yolunu birden yürütmeye çalışan sporcu öğrencilerin, kendilerine özgü ihtiyaçları olan bireyler olduğu düşünüldüğünde, bu çalışmanın amacı sporcu öğrencilerin kariyerlerini sürdürmedeki 
ihtiyaçlarını belirlenmek, spor ve eğitim kariyerlerini sürdürmekte karşılaştıkları sorunları ve beklentilerini ortaya koymaktır.

\section{Yöntem}

İhtiyaç analizi, üretkenlik / verimlilikte oluşan boşlukları tanımlamada ve bu boşluklara işaret eden kayda değer bir öğretim tasarımına gerek olup olmadığına karar vermede kullanılır. Süreç planlama, veri toplama, veri analizi ve final raporu sunma adımlarından oluşur. (Morrison ve ark., 2010, s.32). Nitel araştırma yöntemlerinden açıklayıcı durum çalışması desen olarak seçilmiştir. Bir durumu ve ya olayı kendi sınırları içerisinde analiz etme söz konusu olduğundan, gerçek hayatla ilgili bağlantıları ortaya koyma ve gelecekte yapılabilecek daha kapsamlı bir çalışmanın ön araştırması anlamında bir yol tayin etme imkânı sunduğundan dolayı bu araştırma deseni seçilmiştir (Patton, 2002; Yıldırım \& Şimşek, 2016).

\section{Katılımcılar}

Çalışmanın katılımcıları Giresun Üniversitesi Spor Bilimleri Fakültesi, Beden Eğitimi ve Spor Öğretmenliği Bölümü’nde öğrenim gören sporcu öğrenci havuzundan amaçsal örnekleme yöntemlerinden ölçüt örnekleme ile seçilmiştir. Öğrenciler arasında geçmişte sporcu olup sporu bırakan, veya sakatlık geçirip ara verenlerden ziyade çalışma yapılırken halen aktif sporculuk kariyeri olan öğrenciler seçilmiştir. Spor türü (bireysel / takım) ve cinsiyet bu süreçte ölçüt olarak düşünülmemiştir. Amatör ve ya profesyonel olarak aktif sporculuk hayatına çeşitli kademelerde devam eden 1 Futbolcu, 1 güreşçi, 2 basketbolcu, 4 voleybolcu ve 1 atlet olmak üzere 6 erkek \& 3 kız toplam 9 sporcu-öğrenci çalışmaya katılmıştır.

\section{Veri Toplama Yöntemleri, İnandırıcılık ve Veri Analizi}

Sporcu öğrenciler vize ve final sınavları için çoğunlukla okulda olduklarından, sömestr ortasında ve sonunda olmak üzere toplam iki odak grup görüşmesi gerçekleştirilmiştir. Görüşmede sorulan sorular, çift kariyerli öğrencilerle alakalı literatürde bulunan çalışmalarda değinilen önemli hususlardan derlenmiştir. Örneğin: "Okulunuzla alakalı kulübünüzün (Yönetici, Antrenör vb.) bakış açısı hakkında ne düşünüyorsunuz?” şeklinde sorular yöneltilmiştir. Görüşmeler fakültede bulunan sınıflarda yuvarlak masa düzeni ile yapılarak katılımcıların da müsaadesi ile ses kaydedici ile kayıt altına alınmıştır. Ayrıca sporcu öğrencilerin yansımaları ile beraber araştırmac1, dönem boyunca sporcu öğrencilerle alakalı karşılaştığı ve gözlemlediği hususları yapılandırılmamış alan gözlem notları olarak kaydetmiştir. Verilerin inandırıcılı̆̆ (trustworthiness) için araştırmacının katılımcılarla belli bir süre geçirmiş olması, aynı zamanda birden fazla veri kaynağı (veri üçlemesi-data triangulation) ile sürecin yönetilmesi sağlanmıştır. 
Araştırmacı önyargılarını minimuma indirebilmek için veri toplama sonrası katılımcılara alıntılarının kontrolü (member-checking) sağlanması ve süreç boyunca farklı alanlardan uzman görüşü alınması gibi stratejiler izlenmiştir (Creswell, 2003). Tematik içerik analizi ile sonuçlar elde edilmiştir. Bu süreçte çeşitli şablonlarla kodlanan veriler, belli kategorilerle temalar altında toplandı. Ham verilerin bazılarına alıntılar şeklinde bulgularda da yer verilmiştir. Katılımcıların gizliliği prensibine uygun olarak bulgularda kendilerinden öğrenci 1, öğrenci 2 şeklinde bahsedilmiştir.

\section{Araştırmacının Rolü ve Konumu}

Nitel araştırmalarda araştırmacının kendisi veri toplama aracıdır ve bu durum bir öznellik yaratır. Araştırmacı, çalışmanın özünü bozacak bir etkide bulunmaması için özdüşünümselliğini belirtmelidir (Koca, 2017). Dolayısıyla bu çalışmada araştırmacının konumunun olası etkileri düşünüldüğünde; kendisi iki yıldır beden eğitimi öğretmenliği bölümünde pedagoji dersleri vermektedir ve konuyla alakalı sporcu-öğrencilerle belirli deneyimleri paylaşmaktadır. Geçmekalma notu anlamında bu araştırmanın bir etkisi yoktur. Akla gelebilecek bir başka konu, araştırmacının katılımcılarla eğitim-öğretim ortamı haricinde hiç bir ortak paydası yoktur. Sonuç olarak, sporcu-öğrencilerin ihtiyaçları bütüncül bir bakış açısıyla yansıtılmaya çalışılmıştır.

\section{Bulgular}

$\mathrm{Bu}$ çalışmanın amacı sporcu öğrencilerin kariyerlerini sürdürmekte karşılaştıkları sorunları ve beklentilerini ortaya koymaktır. Veriler 2017-2018 eğitim öğretim yılı birinci döneminin ortası ve sonunda iki kez yapılan yapılandırılmamış odak grup görüşmeleri ile alan gözlem notları ile elde edilmiştir. Dönem ortasında yapılan görüşme daha çok sporculukla odaklı sorularla, dönem sonundaki görüşme ise okul ve eğitim ile alakalı sorularla yapıldı. Verilerin çözümlenmesi sonrası yapılan tematik içerik analizi sonucuna göre üç ana tema ortaya çıkmıştır (Tablo 1): okulkulüp çatışması (1), paydaş beklentileri (2) ve finansal kaygılar (3).

Tablo 1. Temalar ve Kodların Frekans Tablosu

\begin{tabular}{|c|c|c|}
\hline Temalar & Alt temalar & Kodlar (Frekans) \\
\hline \multirow[t]{3}{*}{$\begin{array}{l}\text { Okul-Kulüp } \\
\text { Çatışması }\end{array}$} & a- Okul içi iletişim problemi & $\begin{array}{l}\text { Öğrenci-öğretim üyesi ilişkisi (7) } \\
\text { Öğretim üyesi-öğrenci iletişimi (6) } \\
\text { Öğrenci-öğrenci arası iletişimsizlik (3) } \\
\text { Öğrenci- öğretmen arası iletişimsizlik }\end{array}$ \\
\hline & b-Devamsızlık problemi & $\begin{array}{l}\text { Devamsızlık problemi (5) } \\
\text { Maç tarihlerinin derslerle çakışması } \\
\text { Okulun uzaması } \\
\text { İdmanlarla derslerin çakışması } \\
\text { Yapılan sporun devamsılığa etkisi } \\
\text { Öğrencinin dersi takip etmemesi }\end{array}$ \\
\hline & c-Ulaşım / Lokasyon problemi & Kulübün lokasyonu (2) \\
\hline
\end{tabular}




\begin{tabular}{|c|c|c|}
\hline & & $\begin{array}{l}\text { Ulaşım zorluğu } \\
\text { Okula yakın takım tercihi mecburiyeti } \\
\text { Sporcu-öğrenci olmanın zorluğu }\end{array}$ \\
\hline \multirow[t]{4}{*}{$\begin{array}{l}\text { Paydaş } \\
\text { Beklentileri }\end{array}$} & $\begin{array}{l}\text { a-Sporcu-Öğrencinin öğretim } \\
\text { üyelerinden beklentileri }\end{array}$ & $\begin{array}{l}\text { Öğrencinin öğretim üyesi algısı (2) } \\
\text { Öğrencinin öğretim üyesine karşı tutumu (2) } \\
\text { Öğretim üyesinden insiyatif ve esneklik } \\
\text { beklentisi (3) } \\
\text { Öğrenci- öğretim üyesi iletişimi }\end{array}$ \\
\hline & $\begin{array}{l}\text { b-Ailenin sporcu-öğrencilerden } \\
\text { beklentileri }\end{array}$ & $\begin{array}{l}\text { Ailenin Sporcu- öğrenci ikilemine bakışı } \\
\text { Diploma beklentisi } \\
\text { Okul bitirme sıkıntısı } \\
\text { Aile baskısı (2) } \\
\text { meslek edinme beklentisi (3) }\end{array}$ \\
\hline & $\begin{array}{l}\text { c-Kulüp ve antrenörlerin } \\
\text { beklentisi }\end{array}$ & $\begin{array}{l}\text { Antrenörün okula bakış açısı (2) } \\
\text { Kulüplerin okula bakış açısı (3) } \\
\text { Kulüp yöneticileri ile iletişimsizlik (2) } \\
\text { Yöneticilerin niteliği (2) }\end{array}$ \\
\hline & $\begin{array}{l}\text { d-Sporcu-Öğrencilerin okuldan } \\
\text { beklentisi }\end{array}$ & $\begin{array}{l}\text { Gelecek kaygısı (2) } \\
\text { Sisteme karş1 güvensizlik (3) } \\
\text { Eğitimin niteliği } \\
\text { Öğretim Üyesinin niteliği (3) } \\
\text { Okula karşı aidiyet duygusunun zayıflığ1 }\end{array}$ \\
\hline \multirow[t]{2}{*}{$\begin{array}{l}\text { Finansal } \\
\text { Kaygilar }\end{array}$} & a- Maddi kaygilar & $\begin{array}{l}\text { Sporcunun maddi kaygıs1(3) } \\
\text { Sporcunun gelirine olumsuz etkisi } \\
\text { Maddi kazanç kaybı (2) } \\
\text { Maddi kazanç kaybı kaygısı }\end{array}$ \\
\hline & b - Performans kaygisı & $\begin{array}{l}\text { Derslerle idman arasındaki denge (3) } \\
\text { İş yükünün artması (2) } \\
\text { Derslerle antrenmanın çakışması (2) } \\
\text { Performansa kaygısı (3) }\end{array}$ \\
\hline
\end{tabular}

\section{Okul-Kulüp çatışması:}

Dönem başına 14 haftalık bir süreç olan akademik takvimde \%30 devamsızlık sınırı vardır. Araştırmacının gözlemine göre sporcu öğrenciler genellikle vize ve final haftalarından bir veya iki hafta önce okula gelip ders notları araştırmaktalar. Bu durumda spor kulüplerindeki yönetici ve antrenörlerin önemli rol oynadığ görülmekte:

"Okul ve takım arasında ikilemde kaltyorum ama antrenörüm en azından sınav haftaları için izin veriyor. Yöneticiler de arada dersleri ve bir ihtiyacımız olup olmadiğını soruyorlar. Ama önemli sınavım var dediğimde hoca önemsemiyor, maç daha önemli, bir derse girmesen de olur, ararız okulu konuşuruz diyorlar. " Öğrenci 4, Odak grup görüşmesi 1.

Bu ikilemin diğer ucunda yer alan üniversitedeki öğretim üyelerinin yaklaşımı da süreçteki diğer önemli etmen olarak öne çıkmakta:

"Hocalara bazen ulaşamıyoruz. Maçlar olduğu zaman bazıları olumlu karşılamıyor.

Onların inisiyatifine kalıyor, zor durumda kalıyoruz. Maç, kamp ya da antrenmanlarda 
olduğumuzda yok yazıldığımız halde izin alamayabiliyoruz. Bu da bizi devamsızlık konusunda sıkıntıya sokuyor. Okul sporu ise destek olunuyor, kulüp ise hoş karşılanmıyor." Öğrenci 2, Odak grup görüşmesi 1.

Öğrencilerin birincil kimlikleri sporculuk olarak gözükmektedir denebilir. Zira küçük yaştan itibaren sporla geldikleri için sporu asıl meslekleri olarak edinmekteler. Sezon içerisinde belli bir kondisyonda kalmak ve müsabakalarda yer almaya devam etmek için bir başka öğrenci de bu durumun devamsızlıkla direkt ilişkisini aktarmakta:

“Antrenman yapıp belli bir seviyede kalmak için gitmek zorundayım Bu da direkt devamsızlı̆̆a yansiyor. Bu şekilde okul uzuyor” Öğrenci 3, Odak grup görüşmesi 1.

Özellikle bazı sporcuların üniversite okuduğu ilde antrenman imkânı olmadı̆̆ı, sürekli gidip gelmek zorunda olduğu için kamp ve antrenmanlar ders ve sınav haftalarıyla çakıştığını sonuç olarak derslerden kaldığını görmekteyiz.

"Takım arkadaşlarımla sürekli çalışmam gerekiyor, çalışmadığım zaman bana çok kötü etkisi oluyor. Üniversiteden önce hep Türkiye birincisi oluyordum. Okula girdikten sonra beşinciliğe kadar geriledim. Maça giderseniz sizi bırakırı dendiği zaman biz de sporu bırakıyoruz. Sadece milli takıma izin var deniyor ama Türkiye Şampiyonasına gitmeden ve orada derece yapmadan milli takıma giremeyiz ki." Öğrenci 7, Odak grup görüşmesi 1.

Okul ve sporcu-öğrencinin spor yaptığı kulüp aynı ilde ya da yakın şehirlerde olmak zorunda. Öteki türlü kişi çoğu zaman bir tercih yapmaya itiliyor.

"Sınav düzeni için gözetmen olarak sınıfa girdiğimizde dönem içerisinde görmediğimiz yeni yüzler görüyoruz. Sonradan bu kişilerin profesyonel sporcu olduklarını ve farklı illerde ve takımlardaki antrenman, kamp ve maç trafiğinden ancak sinavdan sinava okula uğrayabildiklerinden dolayı devamsızlık konusunda esneklik için görüşme talepleri ile karşılaşıyoruz.” Alan Gözlem Notları, 3 Kasım 2017.

Araştırmacı olarak öğrencilerden gelen yansımaları ve kendi gözlemlerimi göz önünde bulundurduğumda, küçük yaşlardan itibaren öğrencilerin spora yönlenirken okulu bir engel olarak gördükleri ve iki kariyerden birini tercihe zorlandıkları söylenebilir.

\section{Paydaş beklentileri:}

Spor ve Okul ikileminde iki farklı camia ve iki farklı paydaş grubu göze çarpmaktadır. Sporcuöğrencinin içinden geldiği camiada spor kulüplerinin yöneticileri, menajerler, ama en çok da antrenörler ile birlikte kişinin bu süreçte en büyük destekçisi ama aynı zamanda birer baskı unsuru olarak ailesi ve akranları ile birlikte işin eğitim kısmında yer alan öğretmenler ve öğretim üyeleri okul ve spor ikilemi arasında ilk akla gelenler olmaktadır. Öğrencilerin bir çırak gibi 
zamanla kendi yerlerini alacağını düşünen bazı antrenörler, her daim sporcuların BESYO / Spor bilimleri mezunu olmaları için destekleyici rolde görünmektedirler:

"En başından beri benim spor bilimleri okumamı istiyorlardl. En büyük destekçim onlardt. Ileride onların yerine ben geleceğim için benim de spor bilimleri bitirmişs olmamı istiyorlar." Öğrenci 1, Odak grup görüşmesi 2.

Spor bilimleri eğitimi ile sporun birbirini destekler nitelikte olduğunu konusunda antrenörlerin öğrencileri motive ettikleri sıklıkla ortaya çıkan paylaşımlardan biri oldu:

"Antrenörüm her zaman okumayan adam sporcu olamaz, eğitim görmeyen insanın disiplini olmaz ve sporu anlayamaz der." Öğrenci 2, Odak grup görüşmesi 2.

Hatta kimi zaman sporun geçici bir kariyer olduğu, okulun daha uzun vadeli bir iş imkânı kapısı olarak görüldüğünün sporcu-öğrencilere empoze edildiği söylenebilir:

"Bir spor yöneticim vardı her zaman spor bilimleri okumam için beni destekledi. Filanca kişi ögretmen oldu sen de ol derdi. Okulun sporundan önemli, sporunu önemseme ama geri de kalma derdi." Öğrenci 5, Odak grup görüşmesi 2.

Öte yandan, okul-spor kulübü çatışmasının yol açtığı ana problemlerden biri olarak görülen devamsızlık sorununun, okul yöneticileri tarafından da farklı bir bakış açısıyla karşılandığını görmekteyiz. Bir başka çevresel baskı unsuru olarak ailelerin de çocuklarından diploma beklentileri olduğu düşünüldüğünde, sporcu-öğrencilerin devamsızlık konusundaki probleminin okul yöneticisi tarafindan esnetilmesi öğrencilerin elini rahatlatmaktadır.

"Derece yaptığımız için verilen yemek organizasyonunda rektör, hocalarımıza devamsızlık konusunda bize yardımcı olmalarını söylemiş, bu güzel bir şey.” Öğrenci9,Odak grup görüşmesi 2.

Okulun ve okul isminin sportif faaliyetler aracılığı ile gerek yerel gerekse ulusal basında görünür hale gelmesinin getirdiği marka katma değeri ile okul yöneticisi (rektör) sporcu-öğrencilerin derslerdeki başarılarından ziyade sportif başarılarını önemsediği görülmektedir. Sporcuöğrencilerin de okullarından belli beklentileri olduğu da aşikârdır:

"Ben spor yapmak zorundayım, spor bilimleri fakültesine bu yüzden geldim. Sporumu yapmayacaksam yani diğer fen fakültesindekiler gibi her gün okula gelmek zorundaysam bunun için biraz anlayışlı olmaları gerekiyor." Öğrenci 4, Odak grup görüşmesi 1.

Öğretim üyeleri olarak, devamsız olan öğrencilerin ders takibinde ve ders kazanımları ile alakalı kişisel/mesleki gelişimi için geride kaldıklarını açıkça görmekteyiz. Özellikle sporda elde edilen bir başarı durumunda öğretim üyeleri gerek kişisel anlamda gerek mesleki anlamda bir ikileme düşmekte: 
“Öğretmen yetişstirmede önemli olan dersleri takip edememeleri sporcu öğrencileri düzgün yetiştiremiyoruz kaygısı yaratıyor. Ayrıca dersimden devamsızlıktan kalan öğrenciler varken, sporcu-öğrencilerin devamsızlık için bir ayrıcalık istemesi de etik olarak başka bir ikilem yaratıyor.” Alan gözlem notları, 3 Kasım 2017.

\title{
3. Finansal kaygılar:
}

Okul-kulüp ikilemi ve sporcu-öğrencilerin paydaş beklentilerinin yanında; finansal kaygıların da önemli bir bulgu olarak öne çıktığı görülmektedir. Sporculuğun geçici bir meslek olduğu, ilgili sporla ilgili bir antrenörlük kariyerinin sürdürülmesi beklentisinin olduğu sporcu-öğrenciler tarafindan dile getirilmektedir:

\footnotetext{
“Öğrenci olduğumuz için antrenörlerimizin yanında olamıyoruz, bu da bize düşüs olarak yansıyor. Sporculuk hayatı bir yere kadar. Önemli olan mesleğini eline almak olduğu için antrenörlerimiz de bize bu konuda duyarlılar.” Öğrenci 2, Odak grup görüşmesi 1.
}

Kişilerin yükümlülük altında olduğu belli maddi sözleşmelerin de okula devam konusunda önlerinde önemli bir engel olduğu görülmüştür. Menajerlerin yeni kulüp bulmada yaptığ1 pazarlıklara bile sporcunun öğrenişi olduğu okul ile kulübün aynı şehirde olmaması konu olabilmektedir.

\begin{abstract}
"Bizde mecburiyet var yani profesyonel sözleşmen olduğu için idmana katılmadı̆̆ın zaman ceza bile verebiliyorlar gidip hocaya da açtığın zaman hoca da izin vermiyor belirli miktarda para alıyorsun ciddi paralar döndüğü için hocam ben okula gideyim diyemiyorsun bile yani sadece sinav dönemi izin alabiliyorum onun haricinde izin alamıyorum kesinlikle” Öğrenci 8, Odak grup görüşmesi 2.
\end{abstract}

Gelir seviyesi olarak kaybedilmesi istenmeyen belli meblağlar, sporcu-öğrencileri belirli sorumluluk altına sokmakta:
"Bundan ciddi gelir kazanan bir insanım. Birçok arkadaşımız da ciddi gelirler kazanlyor ve yani ailelerine yardımda bulunuyorlar veya kendilerine gelecek hazırliyorlar parayla belki de ögretmen olsa o paraları kazanamayacak yıllık olarak” Öğrenci 8, Odak grup görüşmesi 2.

Antrenörlük ya da öğretmenlik gibi daha uzun soluklu görülebilen mesleklerin yanında sporculuk kısa olduğu halde geliri daha yüksek imkânlar sunduğundan sporcu-öğrenciler geleceğini düşünürken bir yandan da finansal anlamda belli imkânlardan da uzak kalmak istememektedirler.

“Takımdaki birisi belli bir miktar alırken, onun yarısına senin paran düşüyor çünkü sen ilk başta konuşurken maddi anlamda da düşük allyorsun ki idmana az gidiyorsun zaten senin kendini gösterip daha iyi bir yere gelebilmen için performansını da etkiliyor. Az idmana gitmiş olduğun için süre de alamıyorsun zaten.” Öğrenci 3, Odak grup görü̈smesi 1. 
Anlaşılan spor kulübünün her sene değişme ihtimali olması, kulübün sporcu öğrencinin öğrencisi olduğu okul ile yakın lokasyonlarda olması için kişinin daha düşük ücretlerde oynamaya zorlanabilmesi gibi durumları da ortaya çıkarabilmektedir. Ayrıca sakatlık ve yorgunluk gibi durumlar sadece spor kariyeri değil öğrencilik hayatını da etkileyebilmektedir. Maddiyatla alakalı işin eğitim kısmına bakıldığında öğrencilikten dolayı burs alan sporcu-öğrenciler de var. Okulda belli bir not ortalamasının altına düşen öğrencilerin bursları kesilebiliyor:

“Bugün yanıma gelen bir sporcu-ögrrenci, not ortalamasının biraz daha düsserse sporculuk bursunun kesileceğinden bahsetti ve bunun olmaması için benden ekstra not istedi." Alan gözlem notları, 6 Ocak 2018.

\section{Tartışma ve Sonuç}

$\mathrm{Bu}$ çalışmada elde edilen bulgulara göre yaşanan okul-kulüp çatışması; öğretim üyeleri ile sporcu-öğrenci arasındaki iletişim, görev yapılan spor kulübü ve öğrencisi olunan okulun farklı lokasyonlarda bulunması okulda devamsızlık ve ya spor ortamında geri kalmaya dolayısıyla bireylerde ikileme yol açtığı söylenebilir. Sporcu-öğrencilerin kariyerlerini başarılı bir şekilde sürdürmede yaşadıkları problemlerin odak noktasında iki yoldan birini tercih etmeye itildikleri görülmektedir. Yapılan araştırmalarda öğrencilerin spor kariyerlerinin yanında okul hayatları için ders çalışmaya motive edilmesi ve üniversiteye dahil olduklarının hissettirilmesinin elzem olduğu ortaya konmuştur (Pato ve ark., 2018). Spor ortamlarında okulda geçirdiğinden daha çok zaman geçirmesi sporcu-öğrencide bir kimlik karmaşasına yol açmaktadır. Belirli zorunlu dersler ve not baskısı öğrencilerde okulu uzatmaya ya da bırakmaya kadar gitmektedir (Lally \& Kerr, 2005; Sorkkila, Aunola \& Ryba, 2017). Bu çalışmada da devamsızlık baskısı ile beraber okul ve ders takibinin zorlaşması, aynı zamanda esneklik sağlansa dahi nitelikli bir eğitim ile hayata hazırlanmanın imkânının düşük olması birçok sorunu beraberinde getirmektedir.

Her iki kariyerine de devam etme isteği sporcu-öğrencilerde gözlemlenmektedir. Literatüre bakıldığında, İtalyan ve Sloven sporcu öğrencilerin, eğitim kurumlarının desteği olmadığı halde kariyerlerine devam etmek için yüksek motivasyon sahibi olduğu bulunmuştur (Corrado ve ark., 2012). Bu durum Hong Kong ve Tayvan'daki sporcu öğrencilerle yapılan bir başka çalışma ile açıklanabilir. Yapılan araştırmada çift kariyerli öğrencilerin sosyalleşme deneyimlerinin kariyer gelişimine bireysel (kariyer rolleri, özgüven ve motivasyon), finansal, kültürel, akademik ve bir çok farklı seviyelerde etki ettiği ortaya konmuştur (Sum ve ark., 2017). Bu çalışmada da sporcuöğrencilerin lokasyon sorunu ve finansal kaygılara rağmen okullarına azami sürede katılım gösterme çabası görülebilir. Spor ve okul bir arada gider mi sorusu küçük yaşlardan itibaren öne sürülen ikilemlerden biridir. Hâlbuki Aquilina (2013), Finlandiya, Fransa ve İngiltere'deki 
sporcu öğrencilerle yaptığı çalışmada spor ve eğitim kariyerlerinin aslında birbirine uyumlu ve tamamlayıcı rolleri olduğundan bahsederek; eğitimin spor sonrası kariyere hazırladığı, birbirleri arasında bilgi transferi yapılabildiği, sosyal denge ve uzun vadede entelektüel gelişim sağlaması gibi birçok avantajı olduğunu belirtmiştir. Sporun ve öğrenciliğin, özellikle de spor bilimleri ile alakalı bir okul kariyerinin sporla alakalı bir kariyerle uyum içinde olduğu söylenebilir. İngiltere'de yapılan bir başka araştırmada, sporcu öğrencilerin atletik, akademik, psikolojik ve psiko-sosyal bir geçiş deneyimi yaşadıkları ortaya konmuş ve bunlarla baş etmede öz-farkındalık, sosyal destek ve akademik esneklik gibi stratejiler geliştirdikleri bulunmuştur (Brown ve ark., 2015). Bu çalışma özelinde de kanıta dayalı belli öneriler aşağıda sunulmuştur.

\section{Öneriler}

$\mathrm{Bu}$ araştırma 1şı̆̆ında, sporcu-öğrencilerin kendilerine özgü ihtiyaçları olan ve bu ihtiyaçlara yönelik politika geliştirilmesi gereken bir popülasyon olduğu öne çıkmıştır. Okul ve spor kariyerlerinin bir arada götürülmesi için, her iki meslek grubundaki bireylerin sporcuöğrencilerin bireysel farklılıklarına yönelik yaklaşım geliştirmeleri, yaşanan problemlerin çözüm odaklı bir sürece yönlendirilmesine yardım edecektir. Bu konuda okul-kulüp ikileminde en çok öne çıkan devamsızlık konusunda üniversitelerin esneklik getiren yeni eğitim politikaları geliştirmeleri, ancak bunu yaparken eğitim kazanımlarından ödün vermeden ve öğretim niteliğini düşürmeden yenilikçi yaklaşımları teşvik etmeleri gerekmektedir. Teknoloji ve teknoloji destekli eğitim imkânlarının sürekli olarak geliştiği göz önünde bulundurularak, teknoloji ile bütünleştirilmiş öğretim tasarımları ile sporcu-öğrencilerin desteklenmesine fırsat yaratılmalıdır. Bilgiye ulaşmanın ve paylaşmanın oldukça hızlı olduğu günümüz dünyasında kendine özgü ihtiyacı olan bireylerin farklılıklarına cevap veren yeni öğrenme deneyimleri sunulduğunda, eğitim-öğretim süreçlerinin sürdürülebilir bir potansiyel yaratabileceği öngörülebilir.

\section{Kaynakça}

Arslan, F., Bayraktar, G., \& Akdoğan, S. (2006). Beden eğitimi ve spor yüksekokulunda amatör ve profesyonel spor yapan öğrencilerle aktif spor yapmayan öğrencilerin kişilik özelliklerinin incelenmesi. Atatürk Üniversitesi Beden Eğitimi ve Spor Bilimleri Dergisi, 8(2), 40-47.

Aquilina, D. (2013). A study of the relationship between elite athletes' educational development and sporting performance. The International Journal of the History of Sport, 30(4), 374392.

Bayram, L., Keskin, D. Ö. Y., Kabadayı, M., \& Bostanc1, Ö. (2016). Üniversitede Eğitim Gören Milli Sporcuların Sorunlarının İncelenmesi. Gaziantep Üniversitesi Spor Bilimleri Dergisi, 1(2), 75-84. 
Brown, D. J., Fletcher, D., Henry, I., Borrie, A., Emmett, J., Buzza, A., \& Wombwell, S. (2015). A British university case study of the transitional experiences of studentathletes. Psychology of sport and exercise, 21, 78-90.

Corrado, L., Tessitore, A., Capranica, L., \& Rauter, S. (2012). Motivation for a dual-career: Italian and Slovenian student-athletes. Kinesiologia Slovenica, 18(3).

Creswell, JW. (2003). Research Design: Qualitative, Quantitative and Mixed Methods Approaches. Sage Publications: California.

De Subijana, C. L., Barriopedro, M., \& Conde, E. (2015). Supporting dual career in Spain: Elite athletes' barriers to study. Psychology of Sport and Exercise, 21, 57-64.

Geraniosova, K., \& Ronkainen, N. (2015). The experience of dual career through Slovak Athletes' Eyes. Physical Culture \& Sport. Studies \& Research, 66, 53-64.

Guidotti, F., Cortis, C., \& Capranica, L. (2015). Dual career of european studentathletes: a systematic literature review. Kinesiologia Slovenica, 21(3).

Karakaya, Y. E., Karataş, Ö., Özdenk, Ç., \& Karataş, F. (2013). Üniversiteli sporcu öğrencilerin kariyer değeri algıları. Doğuş Üniversitesi Dergisi 14(1), 86-94.

Koca, C. (2017). Spor Bilimlerinde Nitel Araştırma Yaklaşımı. Spor Bilimleri Dergisi, 28(1), 3048.

Lally, P. S., \& Kerr, G. A., (2005). The career planning, athletic identity and student role identity of intercollegiate student-athletes. Research Quarterly for Exercise and Sport, 76(3), 275285.

McQuown Linnemeyer, R., \& Brown, C. (2010). Career maturity and foreclosure in student athletes, fine arts students, and general college students. Journal of Career Development, 37(3), 616-634.

Morrison, G. R., Ross, S. M., Kemp, J. E., \& Kalman, H. (2010). Designing effective instruction. John Wiley \& Sons.

Pato, A. S., Isidori, E., Calderon, A., \& Brunton, J. (2017). An innovative european sports tutorship model of the dual career of student-athletes. UCAM

Patton, M. Q. (2002). Qualitative evaluation and research methods (3rd ed.). SAGE: Thousand Oaks.

Ryba, T.V., Stambulova, N.B., Ronkainen, N.J., Bundgaard J., \& Selanne, H. (2015). Dual career pathways of transnational athletes. Psychology of Sport and Exercise, 21, 125- 134.

Sorkkila, M., Aunola, K., \& Ryba, T. V. (2017). A person-oriented approach to sport and school burnout in adolescent student-athletes: The role of individual and parental expectations. Psychology of Sport and Exercise, 28, 58-67.

Stambulova, N. B., Engström, C., Franck, A., Linnér, L., \& Lindahl, K. (2015). Searching for an optimal balance: Dual career experiences of Swedish adolescent athletes. Psychology of Sport and Exercise, 21, 4-14.

Sum, R. K. W., Tsai, H. H., Ching Ha, A. S., Cheng, C. F., Wang, F. J., \& Li, M. (2017). SocialEcological Determinants of Elite Student Athletes' Dual Career Development in Hong Kong and Taiwan. SAGE Open, 7(2).

Yıldırım, A. \& Şimşek, H. (2016). Sosyal Bilimlerde Nitel Araştırma Yöntemleri (10. Baskı). Seçkin: Ankara. 